\title{
Perfilhamento como característica mitigadora dos prejuízos ocasionados ao milho pela desfolha do colmo principal
}

\author{
Luís Sangoi(1), Amauri Schmitt(1), Paulo Regis Ferreira da Silva(2), Vitor Paulo Vargas ${ }^{(1)}$, Sérgio Roberto Zoldan ${ }^{(1)}$, \\ Jefferson Viera(1), Clovis Arruda de Souza ${ }^{(1)}$, Gilmar José Picoli Junior ${ }^{(1)}$ e Paula Bianchet ${ }^{(1)}$ \\ (1)Universidade do Estado de Santa Catarina, Centro de Ciências Agroveterinárias, Avenida Luiz de Camões, № 2.090, CEP 88520-000 Lages, SC. \\ E-mail: a2ls@cav.udesc.br, amauri.schmitt@agronomo.eng.br, vitorpvargas@hotmail.com, sr.zoldan@hotmail.com, jefferson.vieira05@hotmail.com, \\ a2cas@cav.udesc.br, gilmarpicoli@yahoo.com.br, paula_bianchet@yahoo.com.br (2)Universidade Federal do Rio Grande do Sul, Faculdade \\ de Agronomia, Avenida Bento Gonçalves, no 7.712, CEP 90001-970 Porto Alegre, RS. E-mail: paulo.silva@ufrgs.br
}

Resumo - O objetivo deste trabalho foi verificar se os perfilhos podem mitigar os prejuízos ocasionados pela desfolha do colmo principal em milho. Os experimentos foram implantados em Lages, SC, em 20/10/2006 e 31/10/2008. O delineamento experimental utilizado foi o de blocos ao acaso, com parcelas subdivididas. Na parcela principal, foram testados dois destinos dos perfilhos: manutenção até a colheita e remoção quando o colmo principal apresentava nove folhas expandidas (V9). Nas subparcelas, avaliaram-se quatro épocas de desfolha do colmo principal: V9, V15 (quinze folhas expandidas), VT (pendoamento) e folhas preservadas até a colheita. Avaliou-se o híbrido P30F53, à densidade de 55 mil plantas por hectare. Determinaram-se: a produtividade total, a do colmo principal e a dos perfilhos. As desfolhas realizadas em V15 e VT diminuíram a produtividade, em comparação ao tratamento sem desfolha, independentemente do destino dos perfilhos. Quando o milho foi desfolhado em V15 e VT, a produtividade total das parcelas em que os perfilhos foram mantidos foi maior do que daquelas em que eles foram removidos. Isto indica que os perfilhos foram benéficos ao colmo principal do milho, quando houve restrições à produção de carboidrato oriundas da perda de área foliar próximo do florescimento.

Termos para indexação: Zea mays, perfilho, massa de grãos, produtividade.

\section{Tillering as a trait to mitigate damages caused to maize by the main stem defoliation}

\begin{abstract}
The objective of this work was to verify if tillers can mitigate damages caused by the main stem defoliation in maize. The experiments were set up in Lages, SC, Brazil, on 10/20/2006 and 10/31/2008. The experimental design was a randomized block with split plots. Two tiller destinations were tested in the main plots: tillers preserved until harvesting, and tillers removed when the main stem had nine expanded leaves (V9). Four main stem defoliation times were assessed in the split plots: V9, V15 (15 expanded leaves), VT (tasseling), and leaf maintenance until harvesting. Hybrid P30F53 was tested at 55 thousand plants per hectare. Total grain yield, tiller grain yield and main stem grain yield were determined. Defoliations performed at V15 and VT decreased total productivity, in comparison to the control, regardless of tiller destination. When the main stem was defoliated at V15 and VT, plots where tillers were kept promoted higher total grain yield than those where tillers were removed. This indicates that tillers were instrumental to maize main stem when there were restrictions to the production of carbohydrates due to leaf area loss close to flowering.
\end{abstract}

Index terms: Zea mays, tiller, grain mass, productivity.

\section{Introdução}

Os perfilhos são ramificações laterais que se desenvolvem a partir de gemas axilares dos nós abaixo da superfície do solo. São estruturas utilizadas pelas plantas da família Poaceae como estratégia para compensação de espaços vazios dentro da comunidade (Li et al., 2003; Almeida et al., 2004). Nas espécies em que o perfilhamento é comum, como o trigo, o arroz e a cevada, os perfilhos são considerados benéficos, pois aumentam o número de inflorescências por área, o que contribui para o incremento do rendimento de grãos (Lafarge, 2000; Chen et al., 2010; Lampayan et al., 2010; Picard et al., 2010).

Entre os cereais de importância econômica, o milho é o de menor capacidade de perfilhamento. Isto se atribui à seleção a que foi submetido pelo homem durante o processo evolutivo do teosinto, em que se priorizou a dominância apical, o que causou a redução do número de ramificações laterais e a concentração de toda a energia da planta no colmo principal (Doebley, 2004). 
Os perfilhos produzidos pelo milho apresentam um atraso na emergência de aproximadamente cinco folhas em relação ao colmo principal (Moulia et al., 1999). Esta assincronia no desenvolvimento fenológico faz com que eles pereçam prematuramente e não produzam grãos (Zekeriya, 2002). Por esta razão, os perfilhos foram considerados agentes de estresse, pois competem por água, luz e nutrientes, durante o período de desenvolvimento vegetativo, drenando fotoassimilados que poderiam ser utilizados pelo colmo principal do milho para a produção de grãos (Sangoi et al., 2009). Este comportamento também foi constatado por Duggan et al. (2005) e Elhani et al. (2007), quando avaliaram cultivares de trigo submetidas à deficiência hídrica ao final do ciclo que promoveu a morte prematura dos perfilhos.

A produtividade do milho no Brasil está muito aquém do potencial produtivo da cultura. Uma das causas para a grande lacuna existente entre o rendimento real e o potencial é a diminuição da superfície fotossinteticamente ativa da cultura ocasionada pela desfolha. A desfolha ocorre em consequência de fatores bióticos, como a lagarta-do-cartucho (Spodoptera frugiperda), ou abióticos, como o granizo. A desfolha limita a interceptação da radiação solar e a produção de fotoassimilados, principalmente quando atinge o milho na fase próxima da floração (Lauer, 2004).

O lançamento de cultivares como a P30F53, híbrido simples de milho mais cultivado no Brasil nas safras 2009/2010 e 2010/2011, com alto potencial produtivo e elevada capacidade de perfilhamento, contradiz o conceito de que os perfilhos são drenos prejudiciais à cultura. Nesses híbridos, os perfilhos podem contribuir diretamente para o rendimento, ao produzir grãos, ou indiretamente com fotoassimilados para o colmo principal, ao ocupar espaços vagos na lavoura (Sangoi et al., 2010).

Os híbridos perfilhadores de milho têm maior área foliar do que aqueles que concentram toda a energia da planta num único colmo (Sangoi et al., 2011a). Por isso, os perfilhos podem atuar como supridores de fotoassimilados em situações de deficiência da fonte ocasionadas pela desfolha do colmo principal. Mesmo sem produzir espigas, os perfilhos contribuem indiretamente, com a alocação de fotoassimilados à espiga. Híbridos que conseguem armazenar e redirecionar açúcares do colmo ou de outra fonte supridora de carboidratos, durante o enchimento de grãos, têm a possibilidade de apresentar maior estabilidade agronômica em condições de estresses bióticos e abióticos que reduzem a área foliar (Sangoi et al., 2001). O redirecionamento de fotoassimilados dos perfilhos para o colmo principal foi reportado por El Alaoui et al. (1992), quanto à cultura do trigo, e por Pasuquin et al. (2008) sobre o arroz irrigado.

O objetivo deste trabalho foi verificar se os perfilhos podem mitigar os prejuízos à produtividade do milho ocasionados pela desfolha do colmo principal.

\section{Material e Métodos}

O experimento foi realizado em campo, no Município de Lages, SC, durante os anos agrícolas de 2006/2007 e 2008/2009. O solo da área experimental é classificado como Nitossolo Vermelho distrófico típico (Santos et al., 2006), com as seguintes características químicas em agosto de 2006: argila, $460 \mathrm{~g} \mathrm{~kg}^{-1}$; $\mathrm{pH}$ em $\mathrm{H}_{2} \mathrm{O}, 6,7$; $\mathrm{P}, 3,3 \mathrm{mg} \mathrm{L}^{-1} ; \mathrm{K}, 0,43 \mathrm{cmol}_{\mathrm{c}} \mathrm{dm}^{-3}$; $\mathrm{MO}, 39 \mathrm{~g} \mathrm{~kg}^{-1}$; $\mathrm{Ca}$, $11 \mathrm{cmol}_{\mathrm{c}} \mathrm{dm}^{-3} ; \mathrm{Mg}, 6,5 \mathrm{cmol}_{\mathrm{c}} \mathrm{dm}^{-3} ; \mathrm{Al}, 0,1 \mathrm{cmol}_{\mathrm{c}} \mathrm{dm}^{-3}$; e CTC, $20,78 \mathrm{cmol}_{\mathrm{c}} \mathrm{dm}^{-3}$.

Utilizou-se o delineamento experimental de blocos ao acaso com parcelas subdivididas e quatro repetições por tratamento. Na parcela principal, foram testados dois destinos dos perfilhos: manutenção até a colheita ou remoção quando o colmo principal estava no estádio V9 (nove folhas expandidas) da escala proposta por Ritchie et al. (1993). Nas subparcelas, foram avaliadas três épocas de desfolha do colmo principal: V9, V15 (quinze folhas expandidas), VT (pendoamento), e mais um tratamento testemunha sem desfolha. Em cada estádio fenológico, as lâminas de todas as folhas com colar, lígula e aurícula visíveis foram removidas manualmente. As subparcelas constituíram-se de cinco linhas com seis metros de comprimento. A área útil tinha três linhas centrais de cada subparcela, com exceção de $0,5 \mathrm{~m}$ na extremidade de cada linha.

Como cobertura de inverno, utilizou-se a aveia-preta (Avena strigosa Scheib). A semeadura da aveia foi feita em maio e resultou na produção de $2.500 \mathrm{~kg} \mathrm{ha}^{-1} \mathrm{e}$ $5.600 \mathrm{~kg} \mathrm{ha}^{-1}$ de massa de matéria seca, em 2006 e 2008 , respectivamente, no momento da dessecação, realizada ao final do mês de setembro de cada ano agrícola.

Os experimentos foram implantados 20/10/2006 e 31/10/2008, no sistema de semeadura direta. A semeadura foi realizada com semeadoras manuais, com três sementes do híbrido P30F53 por cova, com $70 \mathrm{~cm}$ 
de espaçamento entre as linhas. Quando as plantas estavam com três folhas expandidas (V3), procedeuse ao desbaste, a fim de se obter uma população de 55 mil plantas por hectare. As sementes foram tratadas com inseticida à base de imidacloprid + tiodicarbe (45 +186 g ha $^{-1}$ i.a.), para controlar pragas de solo que pudessem prejudicar a emergência da cultura.

A adubação de manutenção foi realizada no dia da semeadura com nitrogênio, fósforo e potássio. As doses aplicadas basearam-se na análise de solo e nas recomendações do manual de adubação e calagem para os Estados do Rio Grande do Sul e Santa Catarina (2004), para uma expectativa de rendimento de $12 \mathrm{Mg} \mathrm{ha}^{-1}$. Foram utilizados $245 \mathrm{~kg} \mathrm{ha}^{-1}$ de $\mathrm{P}_{2} \mathrm{O}_{5}$, $110 \mathrm{~kg} \mathrm{ha}^{-1}$ de $\mathrm{K}_{2} \mathrm{O}$ e $30 \mathrm{~kg} \mathrm{ha}^{-1}$ de $\mathrm{N}$. A cobertura nitrogenada foi feita com ureia e consistiu de duas doses de $100 \mathrm{~kg} \mathrm{ha}^{-1}$ de $\mathrm{N}$, aplicadas às plantas nos estádios V4 e V8 da escala de Ritchie et al. (1993).

Nos dias da semeadura, efetuou-se o controle preventivo de plantas daninhas, tendo-se aplicado uma mistura de atrazina e s-metolaclor $(1.480+$ $1.160 \mathrm{~g} \mathrm{ha}^{-1}$ i.a.). Quando as plantas se encontravam em V3, complementou-se o controle das plantas daninhas com a aplicação do herbicida tembotrione (100,8 g ha $^{-1}$ i.a.). O controle da lagarta do cartucho (Spodoptera frugiperda) foi feito pela aplicação dos inseticidas lufenuron (15 $\mathrm{g} \mathrm{ha}^{-1}$ i.a.) e triflumuron (24 $\mathrm{g} \mathrm{ha}^{-1}$ i.a.), sempre que as plantas apresentavam sintomas de raspagem nas folhas.

Nas subparcelas em que os perfilhos foram mantidos, avaliou-se o número de perfilhos produzidos por planta e a percentagem de plantas perfilhadas, quando o milho se encontrava em V9, V15, VT e no dia da colheita.

A colheita foi feita manualmente, no momento em que todas as folhas das plantas estavam senescidas e a umidade dos grãos era de 18 a $22 \%$. Colheram-se separadamente as espigas produzidas no colmo principal e nos perfilhos. Após a colheita, foi efetuada a trilha dos grãos com uma trilhadeira estacionária. Os grãos foram secos em estufa com ventilação, à temperatura de aproximadamente $65^{\circ} \mathrm{C}$, até que a massa se tornasse constante. Os pesos obtidos foram convertidos para um hectare e expressos na umidade padrão de $130 \mathrm{~g} \mathrm{~kg}^{-1}$. Determinou-se a produtividade total, a do colmo principal e a dos perfilhos. De cada subparcela, uma subamostra de 400 grãos do colmo principal foi retirada e pesada. $\mathrm{O}$ valor obtido foi multiplicado por 2,5 e convertido para $130 \mathrm{~g} \mathrm{~kg}^{-1}$ de umidade, para expressar a massa de 1.000 grãos. Determinou-se o número de grãos por espiga indiretamente, de acordo com a massa de 1.000 grãos, a massa total de grãos e o número de espigas colhidas em cada unidade experimental.

O balanço hídrico da cultura foi realizado com adaptação do cálculo da evapotranspiração potencial (ETP) pela evaporação do tanque classe A, multiplicadas pelo coeficiente do tanque (Kp), que foi obtido experimentalmente na estação meteorológica da Universidade do Estado de Santa Catarina (Udesc). Os dados de registros meteorológicos foram obtidos na estação meteorológica da Udesc, situada a $10 \mathrm{~km}$ de distância da área experimental.

Os dados obtidos foram avaliados estatisticamente pela análise de variância, com o programa estatístico WinStat. Os valores de $\mathrm{F}$ para os efeitos principais e as interações foram considerados significativos a $5 \%$ de probabilidade. Quando alcançada significativas, as médias dos tratamentos foram comparadas pelo teste de Tukey, a $5 \%$ de probabilidade.

\section{Resultados e Discussão}

A época de realização da desfolha não afetou significativamente a percentagem de plantas perfilhadas e o número de perfilhos externados pela planta até o pendoamento (Tabela 1). Isto ocorreu porque a emissão ou a supressão no desenvolvimento dos perfilhos é definida quando a planta se encontra entre V4 e V6 (Moulia et al., 1999). Como as folhas foram removidas nos estádios V9, V15 ou VT, no momento da desfolha os perfilhos já se encontravam em desenvolvimento e mantiveram-se vivos até o florescimento.

As parcelas desfolhadas em VT apresentaram maior percentagem de plantas perfilhadas na colheita do que as parcelas onde as folhas foram preservadas (Tabela 1). Isto mostra que mais plantas mantiveram perfilhos vivos durante o enchimento de grãos, em razão dos danos causados ao colmo principal pela remoção de todas as folhas da planta. Nesse caso, os perfilhos, possivelmente, se beneficiaram da maior incidência de luz e da quebra da dominância apical ocasionada pela desfolha integral do colmo principal. Comportamento semelhante foi reportado por García del Moral \& García del Moral (1995), que observaram maior sobrevivência dos perfilhos em cultivares de cevada, quando as condições de luminosidade e 
disponibilidade hídrica foram adequadas durante o enchimento de grãos.

Os valores numéricos referentes à percentagem de plantas perfilhadas e ao número de perfilhos produzidos por planta, em V9 e na colheita, foram menores no segundo ano agrícola do que no primeiro (Tabela 1). Isto mostra que as condições ambientais em 2006/2007 foram mais favoráveis tanto para a emissão de perfilhos, no início do ciclo, quanto para a sua sobrevivência até a colheita.

Tabela 1. Percentagem de plantas perfilhadas e número de perfilhos por planta em diferentes estádios fenológicos do milho, em função do estádio de desfolha do colmo principal $^{(1)}$.

\begin{tabular}{|c|c|c|c|c|}
\hline $\begin{array}{l}\text { Estádio de } \\
\text { avaliação }^{(2)}\end{array}$ & $\begin{array}{c}\text { Sem } \\
\text { desfolha }\end{array}$ & $\begin{array}{c}\text { Desfolha } \\
\text { em V9 }\end{array}$ & $\begin{array}{l}\text { Desfolha } \\
\text { em V15 }\end{array}$ & $\begin{array}{c}\text { Desfolha } \\
\text { em VT }\end{array}$ \\
\hline & \multicolumn{4}{|c|}{ Ano agrícola 2006/2007 } \\
\hline & \multicolumn{4}{|c|}{ Plantas perfilhadas $(\%)-\mathrm{CV} 20,2 \%$} \\
\hline V9 & 95 & 96 & 95 & $98^{\mathrm{ns}}$ \\
\hline V15 & 92 & 96 & 89 & $98^{\text {ns }}$ \\
\hline VT & 91 & 95 & 94 & $97^{\mathrm{ns}}$ \\
\hline \multirow[t]{2}{*}{ Colheita } & $65 \mathrm{~b}$ & $89 \mathrm{a}$ & $88 \mathrm{a}$ & $88 \mathrm{a}$ \\
\hline & \multicolumn{4}{|c|}{ Número de perfilhos por planta - CV 22,4\% } \\
\hline V9 & 1,9 & 2,2 & 2,1 & $2,0^{\mathrm{ns}}$ \\
\hline V15 & 1,9 & 2,1 & 1,9 & $2,1^{\mathrm{ns}}$ \\
\hline VT & 1,8 & 2,0 & 2,0 & $1,9^{\mathrm{ns}}$ \\
\hline \multirow[t]{3}{*}{ Colheita } & 1,1 & 1,3 & 1,2 & $1,3^{\mathrm{ns}}$ \\
\hline & \multicolumn{4}{|c|}{ Ano agrícola 2008/2009 } \\
\hline & \multicolumn{4}{|c|}{ Plantas perfilhadas (\%) - CV 19,4\% } \\
\hline V9 & 53 & 54 & 50 & $65^{\mathrm{ns}}$ \\
\hline V15 & 44 & 45 & 48 & $58^{\mathrm{ns}}$ \\
\hline VT & 51 & 44 & 44 & $53^{\text {ns }}$ \\
\hline \multirow[t]{2}{*}{ Colheita } & $28 \mathrm{~b}$ & $31 \mathrm{~b}$ & $33 b$ & $52 \mathrm{a}$ \\
\hline & \multicolumn{4}{|c|}{ Número de perfilhos por planta - CV $21,8 \%$} \\
\hline V9 & 0,7 & 0,7 & 0,7 & $0,9^{\text {ns }}$ \\
\hline V15 & 0,7 & 0,7 & 0,7 & $0,8^{\mathrm{ns}}$ \\
\hline VT & 0,7 & 0,6 & 0,7 & $0,7^{\mathrm{ns}}$ \\
\hline Colheita & $0,4 b$ & $0,4 \mathrm{~b}$ & $0,4 b$ & $0,7 \mathrm{a}$ \\
\hline
\end{tabular}

${ }^{(1)}$ Médias seguidas de letras iguais, nas linhas, não diferem significativamente,

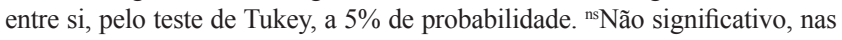
linhas, a 5\% de probabilidade. ${ }^{(2)} \mathrm{V} 9$, nove folhas expandidas; V15, 15 folhas expandidas; VT, pendoamento; desenvolvimento segundo escala de Ritchie et al. (1993).
Dois fatores podem ter contribuído para mitigar a produção de perfilhos, no início do ciclo, em 2008/2009: a grande quantidade de restos culturais de aveia-preta (5.600 $\left.\mathrm{kg} \mathrm{ha}^{-1}\right)$, antes da semeadura do milho, e as menores temperaturas registradas no mês de outubro de 2008 (Tabela 2). Estes fatores retardaram a emergência e o desenvolvimento inicial das plantas. Isto, possivelmente, acentuou a dominância apical e limitou a emissão de perfilhos. Condições de estresse durante o período inicial fazem com que as Poaceae priorizem a alocação de fotoassimilados ao colmo principal (Almeida et al., 2004). Além disso, a restrição hídrica registrada na floração e enchimento de grãos em 2008/2009 (Figura 1), possivelmente, acentuou a morte dos perfilhos, principalmente nas parcelas onde as folhas foram mantidas parcial ou totalmente. Este comportamento também foi reportado por Duggan et al. (2005) e Elhani et al. (2007), que observaram menor sobrevivência dos perfilhos de cultivares de trigo quando as plantas foram submetidas a deficiência hídrica após a antese.

Nos dois anos agrícolas em que se realizou o experimento, o rendimento total de grãos do milho foi afetado pela interação entre o destino dos perfilhos e a época de realização da desfolha, o que evidenciou que o efeito da desfolha, em cada estádio fenológico, depende da manutenção ou retirada dos perfilhos.

A remoção dos perfilhos não incrementou o rendimento de grãos total do milho nos tratamentos sem desfolha (Tabela 3), o que evidencia que essas estruturas não drenaram fotoassimilados do colmo principal que pudessem comprometer o desenvolvimento de sua espiga. No entanto, a manutenção dos perfilhos propiciou rendimentos mais altos do que a sua remoção, quando a planta foi desfolhada em estádios mais avançados de seu ciclo (V15 e VT) e quando a capacidade de regeneração da área foliar do colmo principal é menor.

A desfolha realizada em V9 não reduziu significativamente a produtividade total, em

Tabela 2. Temperatura média mensal do ar $\left({ }^{\circ} \mathrm{C}\right)$, entre outubro e abril, em dois anos agrícolas, em Lages, SC ${ }^{(1)}$.

\begin{tabular}{lcccccccc}
\hline Período & \multicolumn{9}{c}{ Meses do ano } & \multicolumn{2}{c}{ Média } \\
\cline { 2 - 6 } & Outubro & Novembro & Dezembro & Janeiro & Fevereiro & Março & Abril \\
\hline Ano agrícola de 2006/2007 & 17,2 & 17,7 & 19,5 & 20,4 & 20,3 & 19,2 & 15,6 & 18,5 \\
Ano agrícola de 2008/2009 & 16,1 & 17,6 & 19,8 & 19,1 & 21,1 & 20,1 & 15,4 & 18,5 \\
\hline
\end{tabular}

(1)Dados fornecidos pela Empresa de Pesquisa Agropecuária e Extensão Rural de Santa Catarina S.A. - Epagri, Centro Integrado de Meteorologia e Recursos Hídricos de Santa Catarina - Climerh, Estação Agrometeorológica de Lages, SC. 
comparação ao tratamento em que as folhas foram preservadas, tanto na presença quanto na ausência dos perfilhos (Tabela 3). Isso ocorreu, possivelmente, porque o milho tem grande capacidade de regeneração

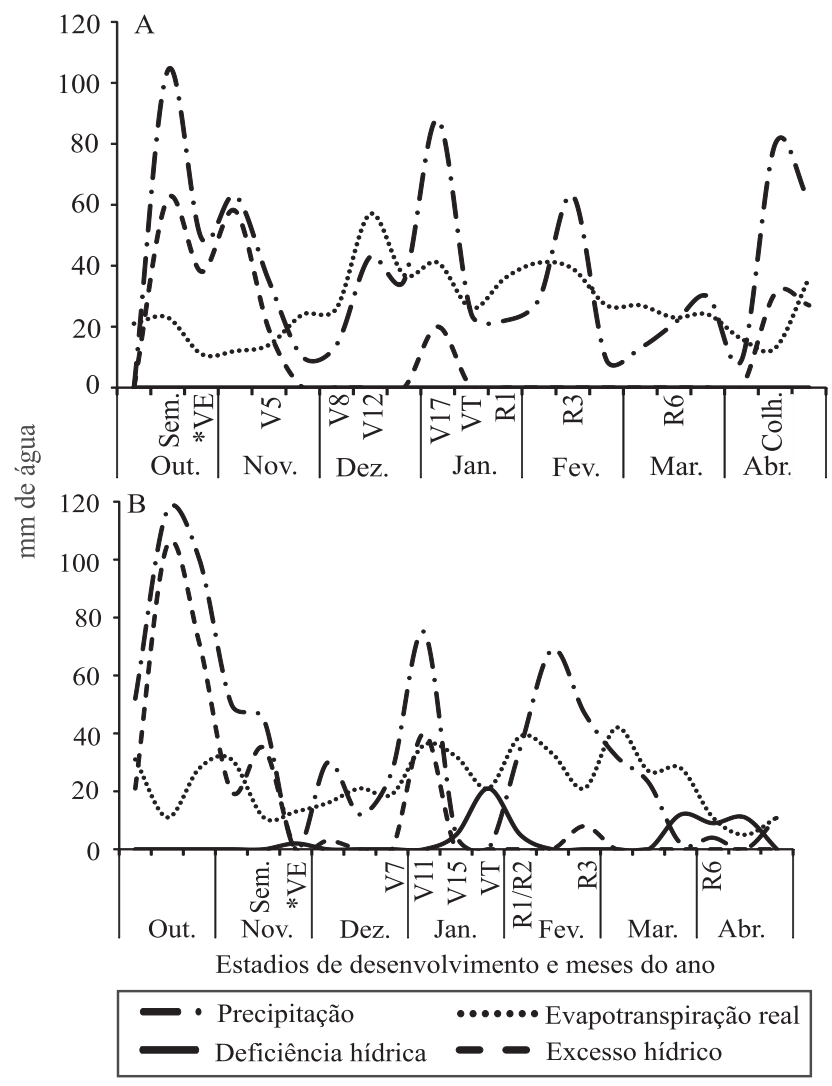

Figura 1. Balanço hídrico decendial dos anos agrícolas de 2006/2007 (A) e 2008/2009 (B), conforme Thorntwaite e Mather, descrita por Bergamaschi et al. (2003), considerandose a capacidade de armazenamento de água de $75 \mathrm{~mm}$ no solo.

Tabela 3. Rendimento total de grãos de milho, em consequência de desfolha, nos estádios ${ }^{(1)} \mathrm{V} 9, \mathrm{~V} 15$ e VT, e da permanência dos perfilhos ${ }^{(2)}$.

\begin{tabular}{|c|c|c|c|c|}
\hline \multirow{2}{*}{$\begin{array}{l}\text { Destino } \\
\text { dos perfilhos }\end{array}$} & \multicolumn{4}{|c|}{ Rendimento total de grãos $\left(\mathrm{kg} \mathrm{ha}^{-1}\right)$} \\
\hline & Sem desfolha & V9 & V15 & VT \\
\hline & \multicolumn{4}{|c|}{ Ano agrícola 2006/2007 - CV 8,2\% } \\
\hline Mantidos & $10.990 \mathrm{Aa}$ & $10.670 \mathrm{Aa}$ & $8.650 \mathrm{Ab}$ & $4.420 \mathrm{Ac}$ \\
\hline \multirow[t]{2}{*}{ Removidos } & $10.830 \mathrm{Aa}$ & $9.540 \mathrm{Aa}$ & $4.690 \mathrm{Bb}$ & $90 \mathrm{Bc}$ \\
\hline & \multicolumn{4}{|c|}{ Ano agrícola 2008/2009 - CV 7,8\% } \\
\hline Mantidos & $12.690 \mathrm{Aa}$ & $11.720 \mathrm{Aa}$ & $7.807 \mathrm{Bb}$ & $1.592 \mathrm{Ac}$ \\
\hline Removidos & $12.159 \mathrm{Aa}$ & $11.176 \mathrm{Aa}$ & $7.003 \mathrm{Bb}$ & $0 \mathrm{Bc}$ \\
\hline
\end{tabular}

(1)V9, nove folhas expandidas; V15, 15 folhas expandidas; VT, pendometo; desenvolvimento segundo escala de Ritchie et al.(1993). (2)Médias seguidas de letras iguais, maiúsculas nas colunas e minúsculas nas linhas, não diferem significativamente pelo teste de Tukey, a $5 \%$ de probabilidade. de área foliar nas fases iniciais do seu ciclo, o que diminui a sua sensibilidade a estresses ocasionados pela desfolha. Comportamento semelhante for reportado por Lauer et al. (2004) e Mangen et al. (2005), que não constataram decréscimo no rendimento de grãos com a remoção das primeiras folhas expandidas da planta. As desfolhas realizadas em V15 e VT diminuíram o rendimento de grãos, em comparação ao tratamento sem desfolha, tanto na presença quanto na ausência de perfilhos.

O rendimento de grãos do colmo principal foi afetado pelo efeito simples do destino dos perfilhos. A manutenção dos perfilhos propiciou incremento da produtividade do colmo principal de $180 \mathrm{~kg} \mathrm{ha}^{-1}$, em 2006/2007, e de $167 \mathrm{~kg} \mathrm{ha}^{-1}$, em 2008/2009, na média dos estádios de desfolha (Tabela 4). Isto mostra que houve contribuição dos perfilhos, por meio da remobilização de fotoassimilados que foram utilizados pelo colmo principal na produção de grãos. Comportamento semelhante foi reportado na literatura por Berry et al. (2003) e Ehdaie et al. (2008) quanto ao trigo, e por Ao et al. (2010) quanto ao arroz irrigado.

Nos dois anos agrícolas, o rendimento de grãos dos perfilhos foi maior quando as plantas foram desfolhadas em VT do que nas demais épocas de desfolha e no tratamento sem desfolha (Tabela 4). A remoção de todas as folhas do colmo principal, no pendoamento, propiciou melhor penetração de radiação solar nas camadas inferiores do dossel. Isto deve ter contribuído

Tabela 4. Rendimento de grãos do colmo principal e dos perfilhos do milho, em consequência de desfolha, nos estádios ${ }^{(1)}$ V9 e VT, e da permanência dos perfilhos ${ }^{(2)}$.

\begin{tabular}{|c|c|c|}
\hline \multirow{2}{*}{$\begin{array}{l}\text { Destino dos } \\
\text { perfilhos }\end{array}$} & \multicolumn{2}{|c|}{ Rendimento de grãos } \\
\hline & Ano agrícola 2006/2007 & Ano agrícola 2008/2009 \\
\hline & \multicolumn{2}{|c|}{ Colmo principal $\left(\mathrm{kg} \mathrm{ha}^{-1}\right)$} \\
\hline Mantidos & $6.450 \mathrm{~A}^{(3)}$ & $7.832 \mathrm{~A}$ \\
\hline Removidos & $6.270 \mathrm{~B}$ & 7.665B \\
\hline \multirow[t]{2}{*}{ CV (\%) } & 11,5 & 10,9 \\
\hline & \multicolumn{2}{|c|}{ Perfilhos $\left(\mathrm{kg} \mathrm{ha}^{-1}\right)$} \\
\hline Sem desfolha & $1.650 \mathrm{C}$ & $391 \mathrm{C}$ \\
\hline V9 & $1.660 \mathrm{C}$ & $294 \mathrm{C}$ \\
\hline V15 & $2.320 \mathrm{~B}$ & $930 \mathrm{~B}$ \\
\hline$\underline{\mathrm{VT}}$ & $3.400 \mathrm{~A}$ & $1.405 \mathrm{~A}$ \\
\hline $\mathrm{CV}(\%)$ & 13,3 & 12,8 \\
\hline
\end{tabular}

Pesq. agropec. bras., Brasília, v.47, n.11, p.1605-1612, nov. 2012 
para a maior atividade fotossintética dos perfilhos, durante o enchimento de grãos, o que propiciou maior percentagem de perfilhos férteis na colheita (Tabela 1).

O número de grãos por espiga e a massa de 1000 grãos do colmo principal foram afetados pela interação entre o estádio de desfolha e o destino dos perfilhos. As desfolhas realizadas em V15 e VT reduziram o número de grãos por espiga, em comparação com as parcelas não desfolhadas e desfolhadas em V9, tanto na presença quanto na ausência dos perfilhos (Tabela 5). O período compreendido entre V15 e VT é importante para a definição do número de óvulos por fileira e para a expansão dos estilo-estigmas (Serpa et al., 2012). A redução da área foliar nesta fase, possivelmente, prejudicou estas duas importantes etapas na formação das espigas e causou a diminuição do número de grãos por espiga e o rendimento de grãos (Tabela 3). A manutenção dos perfilhos propiciou a produção de maior número de grãos por espiga quando o colmo principal foi desfolhado em V15 e VT (Tabela 5). Este componente do rendimento evidenciou, mais uma vez, que houve remobilização de fotoassimilados dos perfilhos ao colmo principal, quando este foi desfolhado em estádios vegetativos mais avançados. Tal comportamento é reforçado pela

Tabela 5. Componentes do rendimento do colmo principal do milho, em consequência de desfolha, nos estádios V9, V15 e VT, e da permanência dos perfilhos ${ }^{(1)}$.

\begin{tabular}{|c|c|c|c|c|}
\hline \multirow{2}{*}{$\begin{array}{l}\text { Estádio de } \\
\text { desfolha }\end{array}$} & \multicolumn{2}{|c|}{ Número de grãos por espiga } & \multicolumn{2}{|c|}{ Massa de 1.000 grãos $(\mathrm{g})$} \\
\hline & $\begin{array}{l}\text { Perfilhos } \\
\text { mantidos }\end{array}$ & $\begin{array}{l}\text { Perfilhos } \\
\text { removidos }\end{array}$ & $\begin{array}{l}\text { Perfilhos } \\
\text { mantidos }\end{array}$ & $\begin{array}{l}\text { Perfilhos } \\
\text { removidos }\end{array}$ \\
\hline & \multicolumn{4}{|c|}{ Ano agrícola 2006/2007 } \\
\hline Sem desfolha & $540 \mathrm{Aa}$ & $532 \mathrm{Aa}$ & $364 \mathrm{Aa}$ & $360 \mathrm{Aa}$ \\
\hline V9 & $445 \mathrm{Ba}$ & $438 \mathrm{Ba}$ & $355 \mathrm{Aa}$ & $350 \mathrm{Aa}$ \\
\hline V15 & $300 \mathrm{Ca}$ & $270 \mathrm{Cb}$ & $345 \mathrm{Aa}$ & $320 \mathrm{Ab}$ \\
\hline VT & $110 \mathrm{Da}$ & $42 \mathrm{Db}$ & $312 \mathrm{Ba}$ & $270 \mathrm{Bb}$ \\
\hline \multirow[t]{2}{*}{ CV (\%) } & \multicolumn{2}{|c|}{10,2} & \multicolumn{2}{|c|}{10,5} \\
\hline & \multicolumn{4}{|c|}{ Ano agrícola 2008/2009 } \\
\hline Sem desfolha & $582 \mathrm{Aa}$ & $583 \mathrm{Aa}$ & $368 \mathrm{Aa}$ & $370 \mathrm{Aa}$ \\
\hline V9 & 581Aa & $555 \mathrm{Aa}$ & $355 \mathrm{Aa}$ & $354 \mathrm{Aa}$ \\
\hline V15 & 391Ba & $343 \mathrm{Bb}$ & $351 \mathrm{Aa}$ & $330 \mathrm{Ab}$ \\
\hline VT & $159 \mathrm{Ca}$ & $0 \mathrm{Cb}$ & $330 \mathrm{Aa}$ & $\mathrm{OBb}$ \\
\hline CV $(\%)$ & \multicolumn{2}{|c|}{4,6} & \multicolumn{2}{|c|}{3,9} \\
\hline
\end{tabular}

${ }^{(1)}$ Médias seguidas por letras iguais, maiúsculas nas colunas e minúsculas nas linhas, não diferem significativamente, entre si, pelo teste de Tukey, a 5\% de probabilidade. V9, nove folhas expandidas; V15, 15 folhas expandidas; VT, pendoamento; desenvolvimento segundo escala de Ritchie et al.(1993). CV, coeficiente de variação. análise da massa de grãos no colmo principal, que foi maior com a manutenção dos perfilhos do que com sua remoção, nas desfolhas realizadas em V15 e VT.

Em geral, os perfilhos atuaram como fonte de fotoassimilados ao colmo principal e contribuíram direta e indiretamente para a produtividade. A contribuição direta dos perfilhos foi maior nas desfolhas mais tardias, em que a restrição imposta ao aparato fotossintético da planta é mais intensa, em consequência do maior número de folhas removido. Mesmo com a seleção feita ao longo dos anos, para que o milho concentre seus fotoassimilados no colmo principal (Doebley, 2004), a desfolha permite maior penetração de radiação solar nos extratos inferiores do dossel, com a redução da dominância apical, e também permite o favorecimento do desenvolvimento dos perfilhos, condições que proporcionam melhor produção de grãos. A contribuição direta dos perfilhos à produtividade do milho foi também observada por Sangoi et al. (2011b), em ambientes com alta disponibilidade de N, e por Sangoi et al. (2010, 2011a), em lavouras implantadas com baixas populações de plantas.

A capacidade dos perfilhos de mitigar o estresse ocasionado pela desfolha do colmo principal depende das condições edafoclimáticas do ano agrícola, as quais influenciam a emissão e a sobrevivência dos perfilhos. Geralmente a emissão dos perfilhos é maior quando há um estabelecimento rápido e uniforme da lavoura. Além disso, a mortalidade dos perfilhos é acentuada por deficiência hídrica na floração e durante o enchimento de grãos, o que minimiza a sua contribuição ao rendimento de grãos.

\section{Conclusões}

1. Os perfilhos não são drenos relevantes que comprometam a produtividade do milho.

2. Os perfilhos mitigam o estresse ocasionado pela desfolha do colmo principal do milho próximo ao florescimento.

\section{Agradecimentos}

Ao Conselho Nacional de Desenvolvimento Científico e Tecnológico, por concessão de bolsas e apoio financeiro. 


\section{Referências}

ALMEIDA, M.L. de; SANGOI, L.; MEROTTO JÚNIOR, A.; ALVES, A.C.; NAVA, I.C.; KNOPP, A.C. Tiller emission and dry mass accumulation of wheat cultivars under stress. Scientia Agricola, v.61, p.266-270, 2004.

AO, H.; PENG, S.; ZOU, Y.; TANG, Q.; VISPERAS, R.M. Reduction of unproductive tillers did not increase the grain yield of irrigated rice. Field Crops Research, v.116, p.108-115, 2010 .

BERGAMASCHI, H.; GUADAGNIN, M.R.; CARDOSO, L.S.; SILVA, M.I.G. da. Clima da Estação Experimental da UFRGS (e região de abrangência). Porto Alegre: UFRGS, 2003. 77p.

BERRY, P.M.; SPINK, J.H.; FOULKES, M.J.; WADE, A. Quantifying the contributions of dry matter from non-surviving shoots in four cultivars of winter wheat. Field Crops Research, v.80, p.111-121, 2003.

CHEN, S.; ZHANG, X.; SUN, H.; REN, T.; WANG, Y. Effects of winter wheat row spacing on evapotranspiration, grain yield and water use efficiency. Agricultural Water Management, v.97, p.1126-1132, 2010.

DOEBLEY, J. The genetics of maize evolution. Annual Review of Genetics, v.38, p.37-59, 2004.

DUGGAN, B.L.; RICHARDS, R.A.; VAN HERWAADEN, A.F.; FETTEL, N.A. Agronomic evaluation of a tiller inhibition gene (tin) in wheat. I. Effect on yield, yield components, and grain protein. Australian Journal of Agricultural Research, v.56, p.169-178, 2005.

EHDAIE, B.; ALlOUSH, G.A.; WAINES, J.G. Genotypic variation in linear rate of grain growth and contribution of stem reserves to grain yield in wheat. Field Crops Research, v.106, p.34-43, 2008.

EL ALAOUI, A.C.; SIMMONS, S.R.; CROOKSTON, R.L. Allocation of photoassimilate by main shoots and nonsurviving tillers in barley. Crop Science, v.32, p.1233-1237, 1992.

ELHANI, S.; MARTOS, V.; RHARRABTI, Y.; ROYO, C.; GRACÍA DEL MORAL, L.F. Contribution of main stem and tillers to durum wheat (Triticum turgidum L. var. durum) grain yield and its components grown in Mediterranean environments. Field Crops Research, v.103, p.25-35, 2007.

GARCÍA DEL MORAL, M.B.; GARCÍA DEL MORAL, L.F. Tiller production and survival in relation to grain yield in winter and spring barley. Field Crops Research, v.44, p.85-93, 1995.

LAFARGE, M. Phenotypes and the onset of competition in spring barley stands of one genotype: daylength and density effects on tillering. European Journal of Agronomy, v.12, p.211-223, 2000.

LAMPAYAN, R.M.; BOUMAN, B.A.M.; DIOS, J.L. de; ESPIRITU, A.J.; SORIANO, J.B.; LACTAOEN, A.T.; FARONILO, J.E.; THANT, K.M. Yield of aerobic rice in rainfed lowlands of the Philippines as affected by nitrogen management and row spacing. Field crops research, v.116, p.165-174, 2010 .
LAUER, J.G.; ROTH, G.W.; BERTRAM, M.G. Impact of defoliation on corn forage yield. Agronomy Journal, v.96, p.1459-1463, 2004.

LI, X.Y.; QIAN, Q.; FU, Z.M.; WANG, Y.; XIONG, G.; ZENG, D.; WANG, X.; LIU, X.; TENG, X.; HIROSHI, F.; YUAN, M.; LUO, D.; HAN, B.; LI, J. Control of tillering in rice. Nature, v.422, p.618-621, 2003.

MANGEN T.F.; THOMISON, P.R.; STRACHAN, S.D. Earlyseason defoliation effects on topcross high-oil corn production. Agronomy Journal, v.97, p.823-831, 2005.

MANUAL de adubação e calagem para os Estados do Rio Grande do Sul e Santa Catarina. 10.ed. Porto Alegre: Comissão de Química e Fertilidade do Solo, 2004. 400p.

MOULIA, B.; LOUP, C.; CHARTIER, M.; ALLIRAND, J.M.; EDELIN, C. Dynamics of architectural development of isolated plants of maize (Zea mays L.), in a non-limiting environment: the branching potential of modern maize. Annals of Botany, v.84, p.645-656, 1999.

PASUQUIN, E.; LAFARGE, T.; TUBANA, B. Transplanting young seedlings in irrigated rice fields: early and high tiller production enhanced grain yield. Field Crops Research, v.105, p.141-155, 2008.

PICARD, D.; GHILOUFI, P.; SAULAS, P.; TOURDONNET, $\mathrm{S}$. Does undersowing winter wheat with a cover crop increase competition for resources and is it compatible with high yield? Field Crops Research, v.115, p.9-18, 2010.

RITCHIE, S.W.; HANWAY, J.J.; BENSON, G.O. How a corn plant develops? Ames: Iowa State University of Science and Technology, 1993. 26p. (Special report, 48).

SANGOI, L.; ALMEIDA, M.L. de; LECH, V.A.; GRACIETTI, L.C.; RAMPAZZO, C. Desempenho de híbridos de milho com ciclos contrastantes em função da desfolha e da população de plantas. Scientia Agricola, v.58, p.271-276, 2001.

SANGOI, L.; SCHWEITZER, C.; SILVA, P.R.F. da; SCHMITT, A.; VARGAS, V.P.; CASA, R.T.; SOUZA, C.A. de. Perfilhamento, área foliar e produtividade do milho sob diferentes arranjos espaciais. Pesquisa Agropecuária Brasileira, v.46, p.710-717, 2011a.

SANGOI, L.; SCHWEITZER, C.; SCHMITT, A.; PICOLI JUNIOR, G.J.; VARGAS, V.P.; VIEIRA, J.; SIEGA, E.; CARNIEL, G. Perfilhamento e prolificidade como características estabilizadoras do rendimento de grãos do milho em diferentes densidades. Revista Brasileira de Milho e Sorgo, v.9, p.254-265, 2010.

SANGOI, L.; VARGAS, V.P.; SCHIMITT, A.; PLETSCH, A.J.; VIEIRA, J.; SALDANHA, A.; SIEGA, E.; CARNIEL, G.; MENGARDA, R.T.; PICOLI JUNIOR, G.J. Disponibilidade de nitrogênio, sobrevivência e contribuição dos perfilhos ao rendimento de grãos do milho. Revista Brasileira de Ciência do Solo, v.35, p.183-191, 2011b.

SANGOI, L.; SCHMITT, A.; SALDANHA, A.; FIORENTIN, C.F.; PLETSCH, A.J.; VIERIA, J.; GATELLI, M.A. Rendimento de grãos de híbridos de milho em duas densidades de plantas com 
e sem a retirada dos perfilhos. Ciência Rural, v.39, p325-331, 2009.

SANTOS, H.G. dos; JACOMINE, P.K.T.; ANJOS, L.H.C. dos; OLIVEIRA, V.A. de; OLIVEIRA, J.B. de; COELHO, M.R.; LUMBRERAS, J.F.; CUNHA, T.J.F. (Ed.). Sistema brasileiro de classificação de solos. 2.ed. Rio de Janeiro: Embrapa Solos, 2006. $306 \mathrm{p}$.
SERPA, M. da S.; SILVA, P.R.F. da; SANGOI, L.; VIEIRA, V.M.; MARCHESI, D.R. Densidade de plantas em híbridos de milho semeados no final do inverno em ambientes irrigados e de sequeiro. Pesquisa Agropecuária Brasileira, v.47, p.541-549, 2012.

ZEKERIYA, A. Effect of tiller removing and plant density on ear yield of sweet corn (Zea mays saccharata Sturt). Pakistan Journal of Biological Sciences, v.5, p.906-908, 2002.

Recebido em 26 de agosto de 2011 e aprovado em 26 de outubro de 2012 